A C T A C H E M I C A S C A N D I N A V I C A $27 \quad(1973) \quad 401-410$

\title{
Crystal Structure of DL-Tyrosine
}

\author{
ARVID MOSTAD and CHRISTIAN RøMMING \\ Department of Chemistry, University of Oslo, Oslo 3, Norway
}

\begin{abstract}
The crystal structure of DL-tyrosine has been determined by X-ray methods using 1180 observed reflections collected by counter methods. The crystals are orthorhombic, space group Pna2 $2_{1}$, with unit cell dimensions $a=20.83_{6} \AA, b=6.81_{0} \AA$, and $c=5.90_{5} \AA$. The structure was solved by direct methods and refined to a conventional $R$-factor of 0.037; estimated standard deviations in bond lengths not involving hydrogen are $0.003 \AA$ and in angles $0.2^{\circ}$. The molecular dimensions are found to be nearly identical with those found for L-tyrosine. The difference in crystal packing between the $\mathrm{L}$ and the $\mathrm{DL}$ form is discussed.
\end{abstract}

7 he preferred conformation of tyrosine is of interest in several biochemical 1 relations and has frequently been discussed. Information on the structure of the molecule in solution is difficult to obtain; one approach to the problem is to examine the molecular structure in various crystal modifications in order to study the influence of the environment on the conformation. For an optically active compound crystals of the active and racemic forms may both be examined.

The conformation of tyrosine in the crystals of L-tyrosine ${ }^{1}$ is different from that in L-tyrosine hydrochloride ${ }^{2}$ but is the same as the one reported for L-phenylalanine hydrochloride ${ }^{3}$ and potassium L-tyrosine- $O$-sulphate dihydrate. ${ }^{4}$ We have now investigated the crystal structure of DL-tyrosine in which the molecular packing necessarily is different from that in L-tyrosine. Furthermore, as the crystal data on L-tyrosine were found to be different from those derived from powder data, ${ }^{5}$ we felt that the crystal data on $D_{L}$ tyrosine arrived at from powder photographs ${ }^{6}$ ought to be checked against single crystal results.

\section{EXPERIMENTAL}

DL-Tyrosine was recrystallized following the same procedure as the one worked out for L-tyrosine. ${ }^{7}$ A single crystal with approximate dimensions $0.2 \times 0.25 \times 0.35 \mathrm{~mm}^{3}$ was mounted with the direction of the largest dimension $(c)$ along the goniometer head axis and used in all the $\mathrm{X}$-ray experiments.

Acta Chem. Scand. 27 (1973) No. 2 
Precession photographs indicate orthorhombic symmetry; space group extinctions are $(0 k l)$ for $k+l$ odd and $(h 0 l)$ for $h$ odd. The absence of centers of symmetry was proved by Wilson statistics; the space group is thus $P n a 2_{1}$.

Unit cell dimensions were determined from diffractometer measurements on $\mathbf{3 0}$ general reflections using $\operatorname{Mo} K\left(\alpha_{1}+\alpha_{2}\right)$ radiation $(\lambda=0.71069 \AA)$. It may be noted that one axis $(6.810 \AA)$ has half the length of that derived from powder data $(13.68 \AA) .^{6}$

The intensity data were recorded with the use of a SYNTEX P1 diffractometer with graphite crystal monochromated $M \circ K$ radiation for 1369 independent reflections with $2 \theta<60^{\circ}$ using the $\omega-2 \theta$ scanning mode with scan speed varying from 2 to $12^{\circ}$ $\min ^{-1}$ dependent on the intensity. The scan range was from $1^{\circ}$ below $2 \theta\left(\alpha_{1}\right)$ to $1^{\circ}$ above $2 \theta\left(\alpha_{2}\right)$ and background counts were taken for half the scan time at each of the scan range limits. Three standard reflections measured after every 50 reflections showed no sys. tematic fluctuation during the experiment. The 1180 reflections greater than $2.5 \sigma(I)$ were considered to be observed; the remaining 189 were excluded from the structure refinement procedure.

The structure determination was based on the program MULTAN written by $P$. Main, M. M. Woolfson and G. Germain. All other computer programs applied are described in Ref. 10.

Atomic form factors used were those of Doyle and Turner ${ }^{8}$ for oxygen, nitrogen, and carbon atoms and of Stewart, Davidson and Simpson ${ }^{\circ}$ for hydrogen.

\section{CRYSTAL DATA}

DL-4-Hydroxyphenylalanine (DL-tyrosine) $\mathrm{C}_{9} \mathrm{H}_{11} \mathrm{O}_{3} \mathrm{~N}$, orthorhombic. $a=$ $20.836(0.0008) \AA ; b=6.810$ (0.002) $\AA ; c=5.905(0.002) \AA . V=837.9 \AA^{3}, M=$ 181.19, $F(000)=384, Z=4, D_{\text {calc }}=1.435 \mathrm{~g} \mathrm{~cm}^{-3}$. Absent reflections: $(0 \mathrm{kl})$ for $k+l$ odd, $(h 0 l)$ for $h$ odd. Space group $P n a 2_{1}$.

\section{STRUCTURE DETERMINATION}

The intensity data were put on an absolute scale by Wilson's statistical method and normalized structure amplitudes were calculated. The 154 of these with $E$-values larger than 1.50 were used as input in the program assembly MULTAN. ${ }^{11}$ Of the solutions obtained the one with the highest figure of merit was used as the basis for an $E$-map which readily indicated the positions of all non-hydrogen atoms. Initial least-squares refinement included the thirteen heavy atoms with isotropic, then anisotropic temperature factors. When the $R$-factor reached 0.05 all hydrogen atoms were assigned coordinates from stereochemical considerations and were included in the further leastsquares calculations with individual isotropic thermal parameters. After five cycles the shifts in the parameters were negligible compared to the corresponding standard deviations. The final conventional $R$-factor was 0.037 and the weighted $R$ was 0.055 . A comparison of observed and calculated structure factors is given in Table 1; the final parameters for non-hydrogen atoms are listed in Table 2 and for hydrogen atoms in Table 3.

Magnitudes and directions of the principal axes of the ellipsoids of vibrations are given in Table 4. An analysis of the thermal parameters showed that the phenol and alanine parts may each be regarded as rigid bodies. The phenol part has the axis of the largest oscillation $\left(4.6^{\circ}\right)$ nearly parallel to the $\mathrm{Ol}-$ $\mathrm{C} 4-\mathrm{C} 1-\mathrm{C} 7$ direction; the alanine part has the corresponding axis $\left(7.9^{\circ}\right)$ parallel to the $\mathrm{C} 8-\mathrm{O} 3$ direction. The bond lengths were corrected for librational effects according to this model. 
Table 1. Observed and calculated structure factors. The columns are $h, k, l, 10\left|F_{\mathrm{o}}\right|$ and $10\left|F_{\mathrm{c}}\right|$.

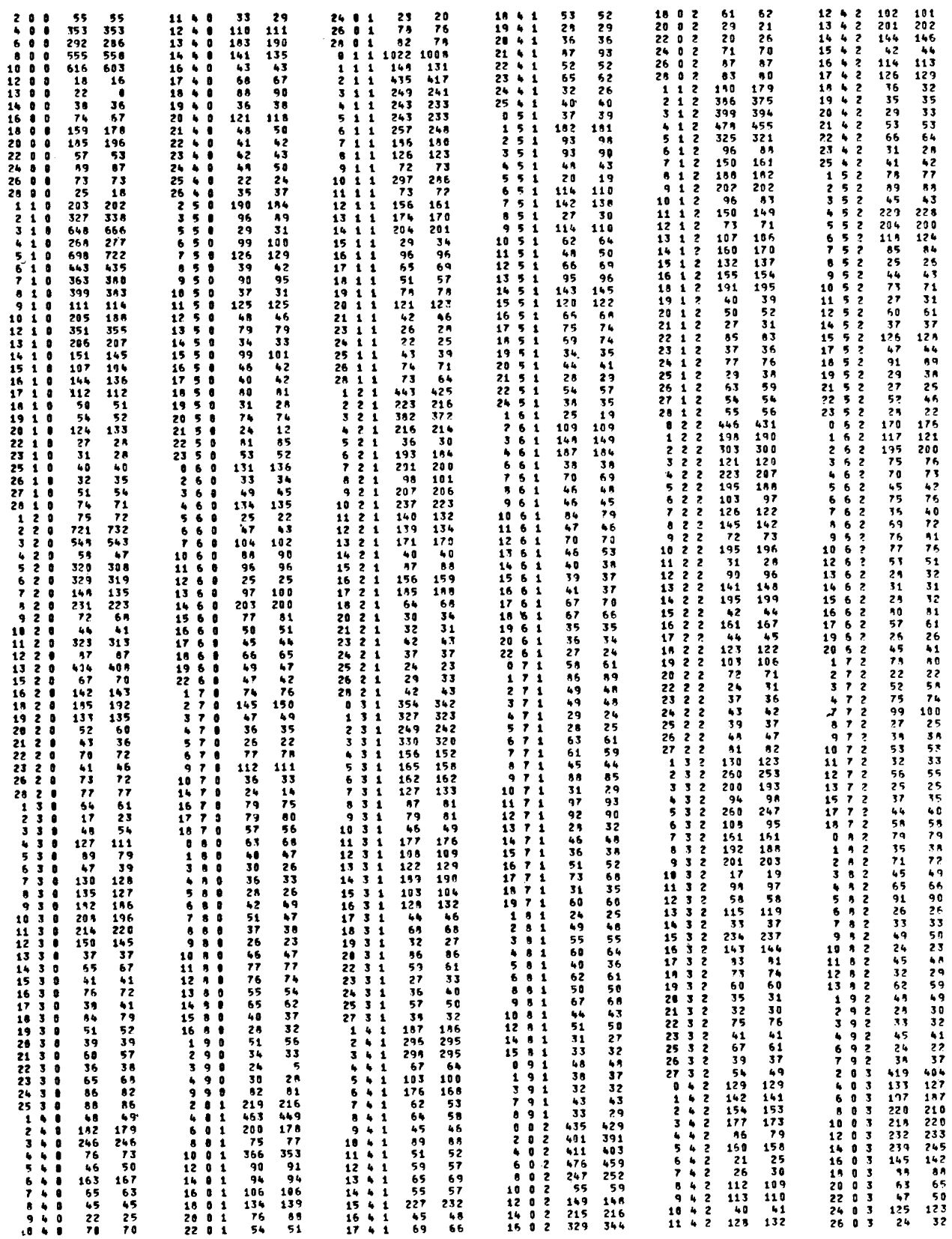

Acta Chem. Scand. 27 (1973) No. 2 
Table 1. Continued.

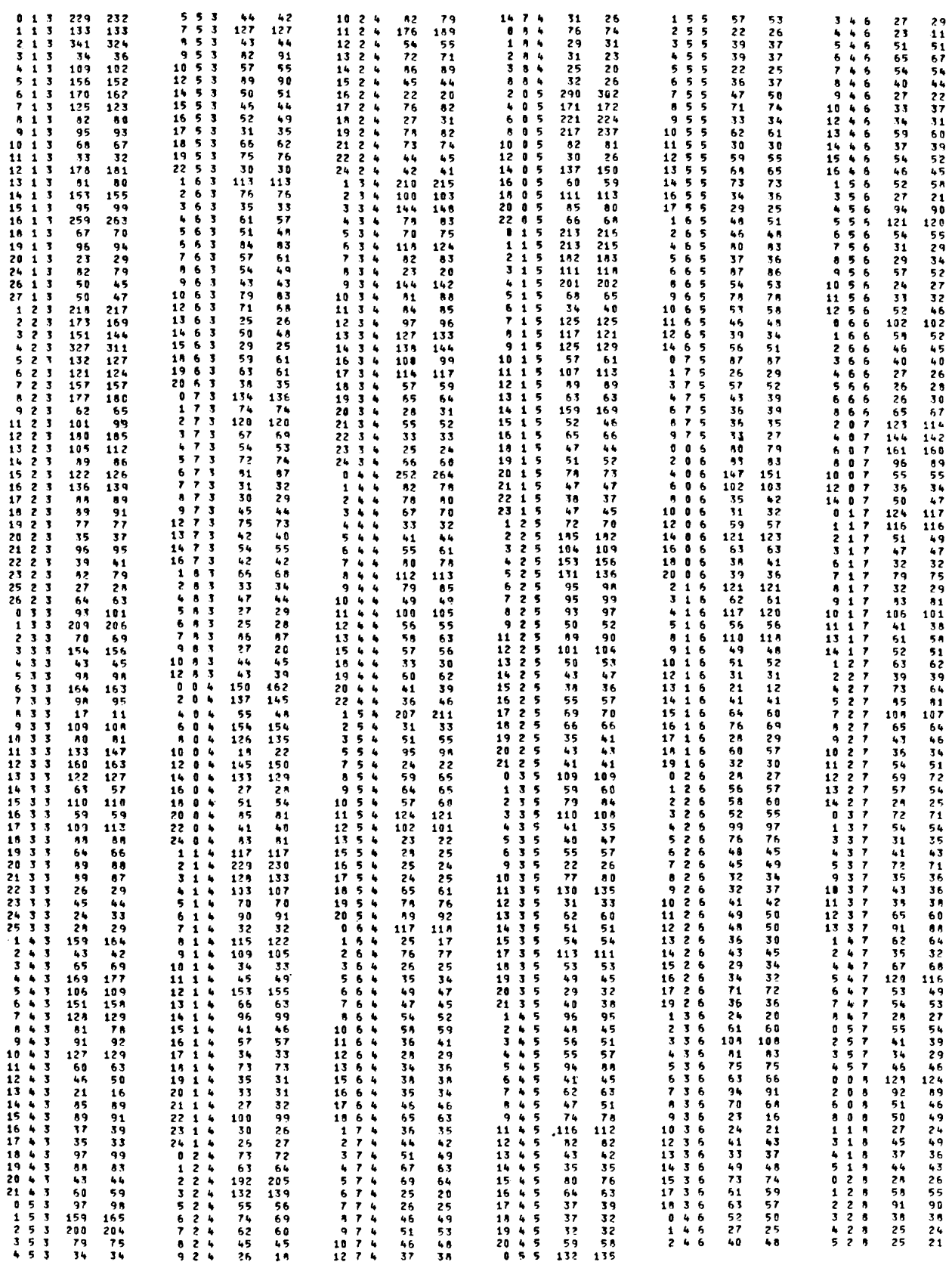


Table 2. Fractional atomic coordinates and thermal parameters with estimated standard deviations $\left(\times 10^{5}\right)$ for non-hydrogen atoms. The temperature factor is given by $\exp -\left(B_{11} h^{2}+B_{22} k^{2}+B_{33} l^{2}+B_{12} h k+B_{13} h l+B_{23} k l\right)$.

\begin{tabular}{|c|c|c|c|c|c|c|c|c|c|}
\hline Atom & $x$ & $y$ & $z$ & $B_{11}$ & $B_{22}$ & $B_{33}$ & $B_{12}$ & $B_{13}$ & $B_{23}$ \\
\hline \multirow[t]{2}{*}{$\mathrm{Ol}$} & -10168 & 73060 & 17400 & 112 & 2000 & 1565 & -117 & -20 & 273 \\
\hline & & 27 & & 3 & 39 & 49 & 17 & 22 & 81 \\
\hline \multirow{2}{*}{$\mathrm{O} 2$} & 17158 & 40200 & 2030 & 169 & 1400 & 1506 & -219 & -126 & -464 \\
\hline & & 24 & 44 & 4 & 31 & 44 & 17 & 22 & 68 \\
\hline \multirow[t]{2}{*}{ O3 } & 21463 & 67438 & -12859 & 161 & 1659 & 1047 & -103 & 51 & 30 \\
\hline & & 25 & 45 & 4 & 34 & 43 & 18 & 21 & 68 \\
\hline \multirow[t]{2}{*}{$\mathrm{N}$} & 19866 & 49323 & 44313 & 113 & 1336 & 949 & 36 & 5 & 116 \\
\hline & 8 & 26 & 45 & 3 & 35 & 40 & 17 & 21 & 71 \\
\hline \multirow[t]{2}{*}{ Cl } & 9488 & 79124 & 28302 & 108 & 933 & 1319 & 45 & 35 & -78 \\
\hline & 9 & 27 & 47 & 4 & 34 & 52 & 18 & 26 & 76 \\
\hline \multirow[t]{2}{*}{$\mathrm{C} 2$} & 6665 & 84401 & 7769 & 117 & 1136 & 1185 & 39 & 161 & 313 \\
\hline & 9 & 30 & 50 & 4 & 37 & 49 & 20 & 26 & 77 \\
\hline \multirow[t]{2}{*}{ C3 } & 96 & 82104 & 4253 & 122 & 1182 & 1284 & 68 & -48 & 202 \\
\hline & 10 & 31 & 52 & 4 & 36 & 57 & 20 & 28 & 83 \\
\hline \multirow[t]{2}{*}{$\mathrm{C} 4$} & -3696 & 74333 & 21334 & 104 & 972 & 1340 & -15 & 31 & -252 \\
\hline & 9 & 29 & 48 & 4 & 35 & 55 & 19 & 26 & 79 \\
\hline \multirow[t]{2}{*}{ C5 } & -970 & 68510 & 41867 & 122 & 1119 & 1247 & -13 & 116 & 314 \\
\hline & 10 & 31 & 52 & 4 & 35 & 53 & 20 & 26 & 78 \\
\hline \multirow[t]{2}{*}{ C6 } & 5619 & 71018 & 45145 & 123 & 1189 & 1151 & 117 & 53 & 284 \\
\hline & 10 & 30 & 48 & 4 & 37 & 50 & 20 & 27 & 76 \\
\hline \multirow[t]{2}{*}{$\mathrm{C} 7$} & 16567 & 82769 & 32339 & 108 & 1115 & 1426 & -30 & 18 & -331 \\
\hline & 9 & 29 & 48 & 4 & 35 & 61 & 19 & 24 & 76 \\
\hline \multirow[t]{2}{*}{$\mathrm{C} 8$} & 20904 & 65017 & 27242 & 87 & 1181 & 850 & -76 & -9 & -81 \\
\hline & 9 & 31 & 47 & 4 & 37 & 45 & 18 & 22 & 74 \\
\hline \multirow[t]{2}{*}{$\mathrm{C} 9$} & 19741 & 56741 & 3502 & 78 & 1294 & 931 & 54 & -58 & -460 \\
\hline & 8 & 30 & 47 & 3 & 39 & 46 & 18 & 21 & 77 \\
\hline
\end{tabular}

Standard deviations in bond lengths and angles were computed from the correlation matrix ignoring standard deviations in cell parameters. For distances and angles the standard deviations were calculated to be $0.003 \AA$ and $0.2^{\circ}$, respectively, except for the bond lengths involving hydrogen where the standard deviation varied from 0.03 to $0.06 \AA$.

\section{DISCUSSION}

A drawing of the molecule is shown in Fig. 1 in which the numbering of the atoms is also indicated. The bond lengths (corrected for thermal effects) and valence angles are given in this figure; interactomic distances and bond angles are also listed in Table 5.

The unit cell dimensions for DL-tyrosine are quite close to those found for L-tyrosine, ${ }^{1}$ and it is interesting to note that the same relation exists between the space groups of $L_{-}$- and DL-tyrosine as that reported for $L_{-}$- and DL-alanine, ${ }^{12}$ viz. $P 2_{1} 2_{1} 2_{1}$ for the optically active crystals and $P n a 2_{1}$ for the racemate. It has recently been pointed out by Pedone and Benedetti ${ }^{13}$ that such relations

Acta Chem. Scand. 27 (1973) No. 2 
Table 3. Fractional coordinates $\left(\times 10^{4}\right)$ and isotropic thermal parameters $\left(\AA^{2}\right)$ with estimated standard deviations for hydrogen atoms.

\begin{tabular}{lrrrr}
\hline Atom & \multicolumn{1}{c}{$y$} & \multicolumn{1}{c}{$z$} & $B$ \\
\hline & & $y$ & & \\
\hline H2 & 984 & 8954 & -479 & 5.3 \\
H3 & 23 & 69 & 112 & 1.2 \\
& -202 & 8587 & -1020 & 2.5 \\
H5 & 13 & 41 & 75 & 0.6 \\
& -367 & 6261 & 5327 & 2.1 \\
H6 & 15 & 40 & 72 & 0.6 \\
H71 & 721 & 6847 & 5787 & 4.5 \\
& 15 & 53 & 87 & 0.8 \\
H72 & 1744 & 8652 & 4920 & 2.4 \\
& 17 & 49 & 91 & 0.9 \\
H8 & 1773 & 9259 & 2367 & 1.6 \\
& 12 & 41 & 65 & 0.6 \\
HO1 & 2511 & 6857 & 3006 & 1.4 \\
& 15 & 41 & 60 & 0.6 \\
HN1 & -1170 & 6871 & 2893 & 5.1 \\
& 18 & 45 & 85 & 0.8 \\
HN2 & 1668 & 4558 & 4428 & 5.8 \\
HN3 & 22 & 65 & 112 & 1.2 \\
& 2018 & 5535 & 5782 & 4.8 \\
& 14 & 45 & 65 & 0.6 \\
& 2284 & 3906 & 4282 & 3.4 \\
\hline
\end{tabular}

Table 4. R.m.s. amplitudes of vibration $\left(\overline{u^{2}}\right)^{\frac{1}{2}}$ and $B$-values $\left(\AA^{2}\right)$ along the principal axes of vibration given by the components of a unit vector $e$ in fractional coordinates $\left(\times 10^{3}\right)$.

\begin{tabular}{|c|c|c|c|c|c|}
\hline Atom & $\left(\overline{u^{2}}\right) \mathbf{\xi}$ & $B$ & $e_{x}$ & $e_{y}$ & $e_{z}$ \\
\hline \multirow{4}{*}{01} & .219 & 3.80 & -9 & 143 & 23 \\
\hline & .165 & 2.15 & 1 & 21 & -168 \\
\hline & .155 & 1.89 & 47 & 26 & 6 \\
\hline & .208 & 3.41 & -38 & 89 & 3 \\
\hline \multirow{3}{*}{$\mathrm{O} 2$} & .181 & 2.60 & 20 & 85 & -118 \\
\hline & .143 & 1.63 & 21 & 81 & 121 \\
\hline & .203 & 3.26 & 26 & -124 & 4 \\
\hline \multirow[t]{3}{*}{$\mathbf{O 3}$} & .182 & 2.63 & 40 & 79 & 17 \\
\hline & .135 & 1.45 & 5 & 5 & -168 \\
\hline & .178 & 2.51 & 9 & 144 & 13 \\
\hline \multirow[t]{3}{*}{$\mathbf{N}$} & .157 & 1.95 & -47 & 28 & 1 \\
\hline & .129 & 1.32 & 0 & 12 & -169 \\
\hline & .158 & 1.97 & 41 & 52 & 66 \\
\hline \multirow[t]{3}{*}{ C1 } & .154 & 1.86 & 8 & 79 & -140 \\
\hline & .143 & 1.61 & -24 & 112 & 68 \\
\hline & .176 & 2.45 & 31 & 86 & 85 \\
\hline \multirow[t]{2}{*}{$\mathrm{C} 2$} & .158 & 1.98 & 29 & -115 & 23 \\
\hline & .132 & 1.37 & 23 & 32 & -145 \\
\hline
\end{tabular}

Acta Chem. Scand. 27 (1973) No. 2 
Table 4. Continued.

\begin{tabular}{|c|c|c|c|c|c|}
\hline \multirow{4}{*}{ C3 } & .173 & 2.36 & 29 & 117 & 18 \\
\hline & .163 & 2.09 & -34 & 68 & 91 \\
\hline & .145 & 1.66 & 18 & -58 & 142 \\
\hline & .162 & 2.07 & 14 & -89 & 124 \\
\hline \multirow[t]{3}{*}{$\mathrm{C} 4$} & .150 & 1.77 & 45 & 41 & -26 \\
\hline & .144 & 1.63 & -5 & 109 & 112 \\
\hline & .171 & 2.32 & 33 & 69 & 93 \\
\hline \multirow[t]{3}{*}{ C5 } & .164 & 2.13 & -29 & 117 & 13 \\
\hline & .137 & 1.49 & 19 & 56 & -141 \\
\hline & .181 & 2.58 & 31 & 107 & 44 \\
\hline \multirow[t]{3}{*}{ C6 } & .153 & 1.85 & -37 & 90 & 28 \\
\hline & .139 & 1.53 & 2 & 44 & -161 \\
\hline & .171 & 2.32 & 10 & -110 & 107 \\
\hline \multirow[t]{3}{*}{ C7 } & .153 & 1.85 & 46 & 1 & -52 \\
\hline & .149 & 1.75 & 11 & 98 & 121 \\
\hline & .169 & 2.25 & 13 & -141 & 9 \\
\hline \multirow[t]{3}{*}{ C8 } & .135 & 1.45 & 46 & 39 & -24 \\
\hline & .122 & 1.18 & 6 & 13 & 167 \\
\hline & .179 & 2.54 & 8 & 138 & -51 \\
\hline \multirow[t]{2}{*}{ C9 } & .132 & 1.38 & -43 & 39 & 63 \\
\hline & .120 & 1.14 & 21 & 30 & 149 \\
\hline
\end{tabular}

may indeed be expected between crystals of the optically active and racemic compounds where virtually identical layers of molecules are packed through the operation of different symmetry elements. This appears to be the case in $L_{-}$- and $D_{L}$-tyrosine, the layer of molecules between the diagonal glide-planes shown in Fig. 3 is nearly the same in both structures. The layers are differently
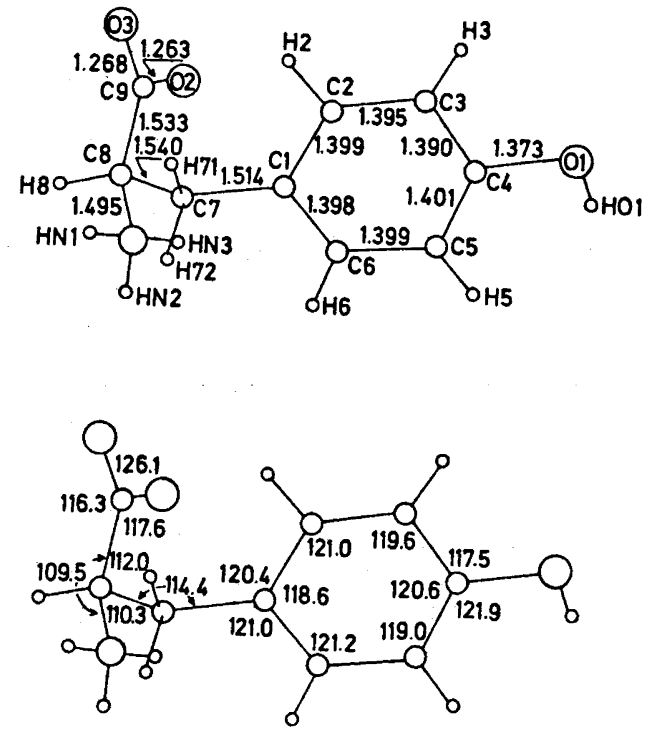

Fig. 1. Bond lengths $(\AA)$ corrected for thermal vibration effects and angles $\left({ }^{\circ}\right)$ in DLtyrosine.

Acta Chem. Scand. 27 (1973) No. 2 
Table 5. Bond lengths $(\AA)$ and bond angles $\left({ }^{\circ}\right)$ in DI,-tyrosine.

\begin{tabular}{|c|c|c|c|c|}
\hline \multirow[b]{2}{*}{$\mathrm{Cl}-\mathrm{C} 2$} & \multirow{2}{*}{ Bond length } & \multirow{2}{*}{ 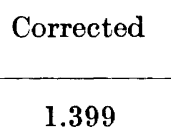 } & \multicolumn{2}{|c|}{ Bond angle } \\
\hline & & & $\mathrm{C} 1-\mathrm{C} 2-\mathrm{C} 3$ & 121.0 \\
\hline $\mathrm{C} 2-\mathrm{C} 3$ & 1.393 & 1.395 & $\mathrm{C} 2-\mathrm{C} 3-\mathrm{C} 4$ & 119.6 \\
\hline $\mathrm{C} 3-\mathrm{C} 4$ & 1.386 & 1.390 & $\mathrm{C} 3-\mathrm{C} 4-\mathrm{C} 5$ & 120.6 \\
\hline $\mathrm{C} 4-\mathrm{C} 5$ & 1.396 & 1.401 & $\mathrm{C} 4-\mathrm{C} 5-\mathrm{C} 6$ & 119.0 \\
\hline $\mathrm{C} 5-\mathrm{C} 6$ & 1.397 & 1.399 & $\mathrm{C} 1-\mathrm{C} 6-\mathrm{C} 5$ & 121.2 \\
\hline $\mathrm{Cl}-\mathrm{C} 6$ & 1.394 & 1.398 & $\mathrm{C} 2-\mathrm{C} 1-\mathrm{C} 6$ & 118.6 \\
\hline $\mathrm{Cl}-\mathrm{C} 7$ & 1.513 & 1.514 & $\mathrm{C} 7-\mathrm{C} 1-\mathrm{C} 2$ & 120.4 \\
\hline $\mathrm{C} 7-\mathrm{C} 8$ & 1.540 & & $\mathrm{C} 7-\mathrm{C} 1-\mathrm{C} 6$ & 121.0 \\
\hline $\mathrm{C} 8-\mathrm{C} 9$ & 1.530 & 1.533 & $\mathrm{O} 1-\mathrm{C} 4-\mathrm{C} 5$ & 121.9 \\
\hline $\mathrm{C} 8-\mathrm{N}$ & 1.485 & 1.495 & $\mathrm{O} 1-\mathrm{C} 4-\mathrm{C} 3$ & 117.5 \\
\hline $\mathrm{C} 9-\mathrm{O} 2$ & 1.251 & 1.263 & $\mathrm{Cl}-\mathrm{C} 7-\mathrm{C} 8$ & 114.4 \\
\hline $\mathrm{C} 9-\mathrm{O} 3$ & 1.262 & 1.268 & $\mathrm{C} 7-\mathrm{C} 8-\mathrm{C} 9$ & 112.0 \\
\hline $\mathrm{C} 4-\mathrm{O} 1$ & 1.371 & 1.373 & $\mathrm{C} 7-\mathrm{C} 8-\mathrm{N}$ & 110.3 \\
\hline $\mathrm{Ol}-\mathrm{HOl}$ & 0.81 & & $\mathrm{~N}-\mathrm{C} 8-\mathrm{C} 9$ & 109.5 \\
\hline $\mathrm{N}-\mathrm{H} I \mathrm{~N}$ & 0.70 & & $\mathrm{C} 8-\mathrm{C} 9-\mathrm{O} 2$ & 117.6 \\
\hline $\mathrm{N}-\mathrm{H} 2 \mathrm{~N}$ & 0.90 & & $\mathrm{C} 8-\mathrm{C} 9-\mathrm{O} 3$ & 116.3 \\
\hline $\mathrm{N}-\mathrm{H} 3 \mathrm{~N}$ & 0.94 & & $\mathrm{O} 2-\mathrm{C} 9-\mathrm{O} 3$ & 126.1 \\
\hline $\mathrm{C} 2-\mathrm{H}_{2}$ & 1.05 & \multirow{3}{*}{\multicolumn{3}{|c|}{ Hydrogen bond lengths }} \\
\hline $\mathrm{C} 3-\mathrm{H} 3$ & 0.99 & & & \\
\hline C5-H5 & 0.97 & & & \\
\hline $\mathrm{C} 6-\mathrm{H} 6$ & 0.84 & $\mathrm{O} 1-\mathrm{O} 2$ & $\left(-x, \quad 1-y, \frac{1}{2}+z\right)$ & 2.668 \\
\hline $\mathrm{C} 7-\mathrm{H} 71$ & 1.04 & $\mathrm{~N}-\mathrm{Ol}$ & $\left(-x, \quad 1-y, \frac{1}{2}+z\right)$ & 2.875 \\
\hline $\mathrm{C} 7-\mathrm{H} 72$ & 0.87 & $\mathrm{~N}-\mathrm{O} 3$ & $\quad x, \quad y, 1+z)$ & 2.833 \\
\hline $\mathrm{C} 8-\mathrm{H} 8$ & 0.92 & $\mathrm{~N}-\mathrm{O} 3$ & $\left(\frac{1}{2}-x,-\frac{1}{2}+y, \frac{1}{2}+z\right)$ & 2.856 \\
\hline
\end{tabular}

packed, however, as may be expected since all layers in $\mathrm{L}_{\text {- }}$-tyrosine are identical whereas the layers in DL-tyrosine consist alternatingly of $D$ and $L$ forms. The difference in packing is visualized in Figs. 2 (A) and (B) which show the coupling of molecules of different layers through the alanine parts; (A) shows the conditions in $\mathrm{L}$-tyrosine as viewed along the $a$-axis $(6.913 \AA)$ and (B) represents the DL-tyrosine structure as viewed down the $b$-axis $(6.810 \AA)$. The pertinent symmetry elements responsible for the coupling of layers are screw axes and glide-planes, respectively. The molecular packing is somewhat denser in the racemate, the density being $1.435 \mathrm{~g} \mathrm{~cm}^{-3}$ as compared to $1.414 \mathrm{~g} \mathrm{~cm}^{-3}$ for L-tyrosine.

The bond lengths and angles found in the present investigation are nearly identical to those determined from the study of the $I_{-}$-form. Except for the $\mathrm{C} 9-\mathrm{O} 2$ bond in the carboxyl group the differences in corresponding bonds are insignificant, $0.008 \AA$ or less; the $\mathrm{C} 9-\mathrm{O} 2$ bond is found $0.017 \AA$ longer than in L-tyrosine. The differences in corresponding angles are $0.7^{\circ}$ or less, the largest dissimilarities are found in the alanine moiety. The conformation in the two structures are also equal; the angle between the phenyl ring plane and the plane defined by the $\mathrm{Cl}-\mathrm{C} 7-\mathrm{C} 8$ atoms is $85.8^{\circ}$ (as compared to $85.9^{\circ}$ in $\mathrm{L}$-tyrosine), the dihedral angles $\mathrm{Cl}-\mathrm{C} 7-\mathrm{C} 8-\mathrm{C} 9$ and $\mathrm{Cl}-\mathrm{C} 7-\mathrm{C} 8-\mathrm{N}$ are $52.5^{\circ}$ and 290.3 , respectively $\left(53.1^{\circ}\right.$ and $290.7^{\circ}$ in $L$-tyrosine $)$ whereas the torsional angle $\mathrm{N}-\mathrm{C} 8-\mathrm{C} 9-\mathrm{O} 2$ is $11.7^{\circ}, 2.3^{\circ}$ less than the corresponding angle in $\mathrm{L}$-tyrosine. 

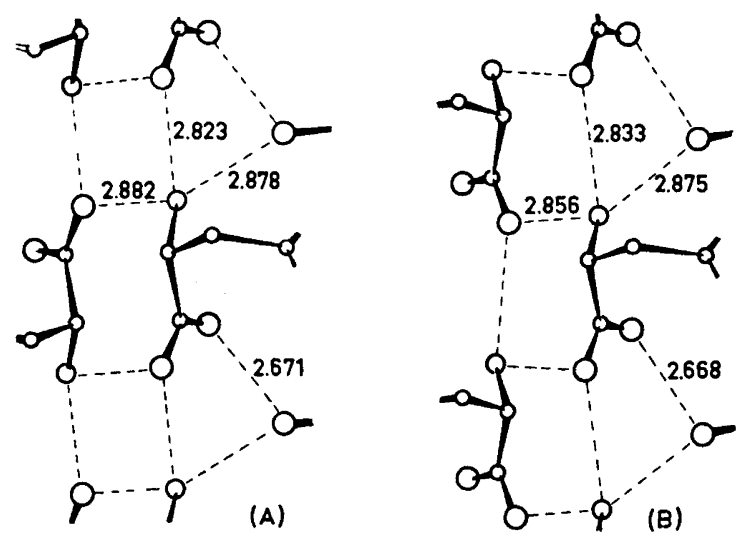

Fig. 2. Molecular arrangement in L-tyrosine (A) and in DL-tyrosine (B) crystals.

The hydrogen bond system in the crystals of DL-tyrosin is shown in Fig. 3. Each molecule is hydrogen donor as well as acceptor in four hydrogen bonds in such a way that one molecule is hydrogen bonded to six neighbouring molecules. The hydrogen bond lengths (given in Table 5) within the layers of molecules of equal chirality are nearly the same as the corresponding bonds in L-tyrosine; the hydrogen bonds linking the layers together are by $0.026 \AA$ shorter in the racemate than in the crystals of the $L_{-}$-form.

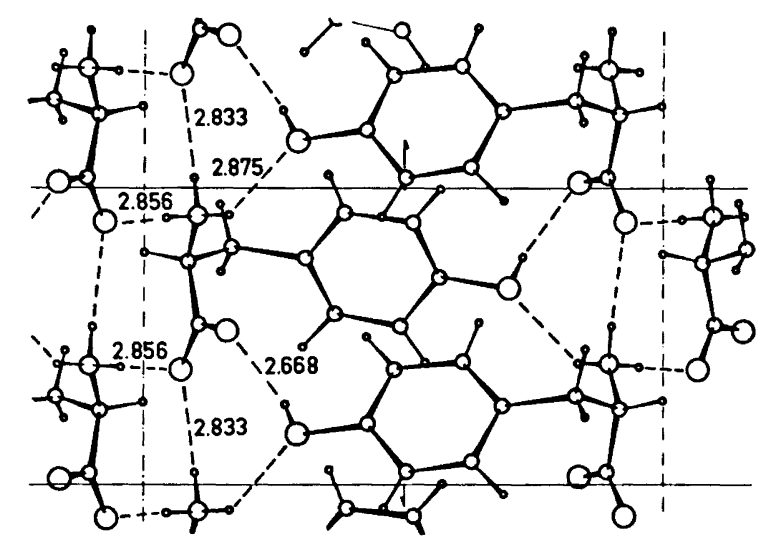

Fig. 3. The crystal structure of DL-tyrosine as viewed along the $b$-axis.

\section{REFERENCES}

1. Mostad, A., Nissen, H. M. and Rømming, C. Acta Chem. Scand. 26 (1972) 3819.

2. Srinsivasan, R. Proc. Indian. Acad. Sci. A 50 (1959) 19.

3. Vainshtain, B. K. and Gurskaya, G. V. Dokl. Akad. Nauk. SSSR 156 (1964) 312.

Acta Chem. Scand. 27 (1973) No. 2 
4. Fries, D. C. and Sundaralingam, M. Acta Cryst. B 27 (1971) 401.

5. Khawas, B. and Krishna Murti. Acta Cryst. B 25 (1969) 1006, 2663.

6. Khawas, B. Acta Cryst. B 26 (1970) 1919.

7. Mostad, A., Nissen, H. M. and Rømming, C. Acta Chem. Scand. 25 (1971) 1145.

8. Doyle, P. A. and Turner, P. S. Acta Cryst. A 24 (1968) 390.

9. Stewart, R. F., Davidson, E. R. and Simpson, W. T. J. Chem. Phys. 42 (1965) 3175.

10. Dahl, T., Gram, F., Groth, P., Klowe, B. and Rømming, C. Acta Chem. Scand. 24 (1970) 2232.

11. Germain, G., Main, P. and Woolfsen, M. M. Acta Cryst. A 27 (1971) 368.

12. Simpson, H. J. and Marsh, R. E. Acta Cryst. 20 (1966) 550.

13. Pedone, C. and Benedetti, E. Acta Cryst. B 28 (1972) 1970.

Received August 11, 1972. 